\title{
Donor-Related Risk Factors and Preoperative Recipient-Related Risk Factors for Graft Failure
}

\author{
Alice L. Yu, MD, ${ }^{*}$ Michaela Kaiser, ${ }^{*}$ Markus Schaumberger, PhD, ${ }^{*}$ Elisabeth Messmer, MD, * \\ Daniel Kook, MD,* and Ulrich Welge-Lussen, MD†
}

Purpose: The aim of this study was to evaluate the outcome of penetrating keratoplasties, at the University Eye Hospital, LudwigMaximilians-University, Munich, Germany, using organ-cultured donor corneas and to identify preoperative risk factors, which may influence the event of graft failure.

Methods: In this study, 377 medical records of patients, who underwent penetrating keratoplasty between 2001 and 2011, were reviewed. Organ-cultured donor corneas were obtained from the eye bank, Ludwig-Maximilians-University, Munich, Germany. Donorrelated and preoperative recipient-related risk factors for graft failure were analyzed by univariate and multivariate analyses.

Results: Graft failure occurred in $26 \%$ of patients. The following preoperative factors were significantly associated with graft failure by multivariate analyses: high donor age, low donor endothelial cell density, high patient age, indications of infectious keratitis, acute perforation of noninfectious keratitis, prior graft failure, chemical burn, trauma, glaucoma-associated corneal decompensation, highrisk graft indications, corneal edema, anterior chamber lens, diabetes mellitus, atopy, and autoimmune diseases.

Conclusions: This study demonstrated a success rate of $74 \%$, which is consistent with previous studies. Various preoperative recipient-related factors seem to influence the outcome of penetrating keratoplasties, whereas few donor-related factors have a significant association with graft failure.

Key Words: penetrating keratoplasty, graft failure, risk factor, donor cornea, eye bank

(Cornea 2014;33:1149-1156)

P enetrating keratoplasty is still the most common corneal transplantation procedure. In comparison with other tissue transplantation procedures, penetrating keratoplasties have a high success rate because of the avascularity of the cornea and the immune privilege in the anterior chamber of the eye. ${ }^{1,2}$

Received for publication April 10, 2014; revision received June 22, 2014; accepted June 27, 2014. Published online ahead of print August 29, 2014.

From the *Department of Ophthalmology, Ludwig-Maximilians-University, Munich, Germany; and $\dagger$ Department of Ophthalmology, FriedrichAlexander-University, Erlangen, Germany.

The authors have no funding or conflicts of interest to disclose.

Reprints: Alice L. Yu, MD, Department of Ophthalmology, LudwigMaximilians-University, Mathildenstrasse 8, 80336 Munich, Germany (e-mail: alice.yu@med.uni-muenchen.de).

Copyright (C) 2014 by Lippincott Williams \& Wilkins
Nonetheless, graft failure may occur in the immediate postoperative period or many years after corneal transplantation. Because the outcome of corneal transplantation is dependent on multiple factors, various studies have identified both preoperative and postoperative risk factors for graft failure..$^{3-6}$

Since its introduction by Zirm in $1905,{ }^{7}$ the number of penetrating keratoplasties has raised increasingly. Every year, 4000 to 5000 penetrating keratoplasties are performed in Germany ${ }^{8}$ and up to 100,000 corneal transplantation worldwide. ${ }^{9,10}$ The availability of such a high number of corneal transplants can only be achieved in cooperation with eye banks, which are responsible for the acquisition, storage, and allocation of corneal transplants. The eye bank of the University Eye Hospital, Ludwig-Maximilians-University, Munich, Germany, was founded in 1999 and provided more than 1000 corneal transplants between 1999 and 2011. Since 1999, organ-cultured media have been exclusively used to store donor corneas in our eye bank. In organ culture preservation, donor corneas are stored in an incubator at 30 to $37^{\circ} \mathrm{C}$. The donor corneas are placed in tissue culture medium supplemented with fetal calf serum, antibiotics, and antimycotics. In contrast to the hypothermic storage preservation, which only allows the corneas to be stored for up to 2 weeks, organ culture offers a longer storage time for up to 4 weeks.

Since the foundation of our eye bank more than 10 years ago, no studies have yet been conducted to evaluate the outcome of penetrating keratoplasties with the organ-cultured donor corneas from our eye bank. For this reason, we investigated the outcome of penetrating keratoplasties with donor corneas of our eye bank and analyzed the risk factors for graft failure among our patient population. In this study, we concentrated on potential preoperative risk factors including donor risk factors and preoperative risk factors of the recipients. Knowledge about the preoperative risk factors for graft failure in penetrating keratoplasties may provide a better preoperative assessment of the surgeon and improved education of the patients about individual risks for their forthcoming penetrating keratoplasty.

\section{PATIENTS AND METHODS}

This is a retrospective analysis of the medical records of 1030 consecutive patients who underwent penetrating keratoplasty at the University Eye Hospital, Ludwig-MaximiliansUniversity, Munich, Germany, between 2001 and 2011. All donor corneas came from the eye bank of our University Eye Hospital. This study was performed in accordance with the 
ethical standards laid down in the 1964 Declaration of Helsinki and was approved by the local ethics committee. Of the total 1030 medical records, which were reviewed, only 377 medical records documenting a follow-up period of at least 1 year were included into this study. The follow-up period was defined as the period between the day of surgery and the day when graft failure was diagnosed. In case of nonfailure, the follow-up period was the period between the day of surgery and the last documented follow-up visit. Every patient was included in this study for only 1 time. In case a patient received penetrating keratoplasties in both eyes, only the first operated eye was included.

Follow-up data were collected from the following time points: at least 1 month after surgery, 3 months after surgery, and 1 year after surgery. The exclusion criteria were patients with nonpenetrating forms of keratoplasty and patients with a follow-up of less than 1 year. The following data were collected from the medical records: demographic data (age, gender), ocular history (indication for surgery, corneal edema, corneal vascularization, anterior synechia, lens status, preoperative history of ocular diseases, previous eye surgeries), and history of systemic diseases. All penetrating keratoplasties were performed by the 3 most experienced surgeons of our hospital during this 10-year study period.

Since the foundation of the eye bank of the LudwigMaximilians-University, Munich, Germany, in 1999, only organ-cultured donor corneas were used for all penetrating keratoplasties. All corneal tissues were recovered by enucleation of the whole eye, stored in organ culture at $37^{\circ} \mathrm{C}$, and had an endothelial cell density of at least 2000 cells per square millimeter before transplantation.

Data concerning donor-related risk factors were collected in the eye bank and included donor age, death to enucleation time, storage time, endothelial cell density, and assessment of clarity and rigidity of the donor cornea by the surgeon. For the assessment of clarity of the donor cornea, the surgeon was asked to set the answer on a $5 \mathrm{~cm}$ horizontal line with $0 \mathrm{~cm}$ representing "clear" and $5 \mathrm{~cm}$ representing "blurred." For the assessment of rigidity, $0 \mathrm{~cm}$ represented "rigid" and $5 \mathrm{~cm}$ represented "soft." The clarity and rigidity of the cornea should describe the surgeon's opinion of the condition of the cornea before surgery.

Statistical analyses were conducted with the IBM SPSS Statistics Version 21.0 (IBM SPSS, Armonk, NY). Descriptive statistics were used for the calculation of mean values and standard deviations. Cox univariate regression analyses were conducted for each variable. Graft failure was the primary endpoint. Graft failure was defined as an existing graft, which required a repeat keratoplasty or became irreversibly edematous and opaque with an irremediable loss of clarity. Variables with $P \leq 0.01$ were further tested in the Cox multivariate regression analysis with a backward selection procedure to identify potential risk factors for graft failure. The effect of each variable was quantified by hazard ratio (HR). Correlations between variables were examined by Pearson linear regression analysis. Chi-square tests and Fisher exact tests were performed for analyses of categorical variables. $P<0.05$ was regarded as statistically significant.

\section{RESULTS}

\section{Donor-Related Risk Factors for Graft Failure}

The mean age of all donors was $44.6 \pm 16.4$ years, whereas the mean donor age for graft failure was $49.6 \pm$ 16.6 years, and the mean donor age for non-graft failure was $42.8 \pm 16.2$ years. Based on our analyses, increasing donor age was significantly associated with graft failure $(\mathrm{HR}=$ 1.02, $P<0.001)$. Besides that, a lower endothelial cell density was also a significant factor for graft failure (HR = $0.99, P=0.004)$. There was no significant difference in the influence on graft failure between endothelial cell densities $\leq 3000$ cells per square millimeter and $>3000$ cells per square millimeter. Because donor age and endothelial cell density had a highly significant negative association (Pearson correlation, $P<0.001, \mathrm{r}=-0.382$ ), a multivariate analysis of these 2 correlating variables was not performed. In contrast, death to enucleation time and storage time were found to be nonsignificant. Besides that, the surgeons' assessment of the donor corneas in terms of clarity and rigidity was also not a significant factor for graft failure (Table 1).

\section{Demographic and Baseline Characteristics}

In total, 377 patients with a penetrating keratoplasty with organ-cultured donor corneas from our eye bank were included in this study during the period 2001 to 2011. Of them, 100 patients $(26.5 \%)$ experienced a graft failure. The

TABLE 1. Univariate Analysis of Donor Variables

\begin{tabular}{|c|c|c|c|c|c|}
\hline \multirow[b]{2}{*}{ Donor Variables } & \multirow[b]{2}{*}{ Total (Mean Value) } & \multirow[b]{2}{*}{ Graft Failure (Mean Value) } & \multicolumn{3}{|c|}{ Univariate Analysis } \\
\hline & & & $P$ & HR & $95 \% \mathrm{CI}$ \\
\hline Donor age, per 5 years & 44.6 & 49.6 & $<\mathbf{0 . 0 0 1}$ & 1.26 & $1.14-1.44$ \\
\hline Death to enucleation time, $\mathrm{hr}$ & 25.5 & 25.1 & 0.899 & 0.99 & $0.98-1.02$ \\
\hline Endothelial cell density, per 100 cells $/ \mathrm{mm}^{2}$ & 2694 & 2648 & 0.008 & 0.80 & $0.68-0.94$ \\
\hline Storage time, $\mathrm{d}$ & 19.26 & 19.23 & 0.973 & 0.99 & $0.96-1.04$ \\
\hline Clarity of donor cornea & 2.0 & 2.0 & 0.687 & 0.92 & $0.61-1.38$ \\
\hline Rigidity of donor cornea & 2.5 & 2.6 & 0.930 & 0.99 & $0.72-1.35$ \\
\hline
\end{tabular}

$\mathrm{CI}$, confidence interval. 
mean follow-up period was $39.3 \pm 32.2$ months. The median follow-up period was 27 months. The mean age of all patients was $51.3 \pm 23.5$ years. The mean age of the patients with graft failure was $60.2 \pm 20.5$ years. The non-graft failure patients were significantly younger $(48.0 \pm 23.7$ years; $P<0.001)$. Of the total 377 patients, $228(60.5 \%)$ were men and $149(39.5 \%)$ were women. This gender distribution was similar in the graft failure and non-graft failure group. Whereas 179 patients $(47.5 \%)$ received penetrating keratoplasty in their right eye, 198 patients $(52.5 \%)$ had a keratoplasty on their left eye. This distribution was comparable among the graft failure and non-graft failure patients. There were 28 children between 4 months and 13 years of age who underwent penetrating keratoplasty. The most common indication among the patients with graft failure was preoperative graft failure in 21 patients $(21.0 \%)$. Nineteen patients $(19.0 \%)$ with graft failure had infectious keratitis and 14 patients $(14.0 \%)$ an imminent or acute perforation of noninfectious corneal ulceration. Bullous keratopathy accounted for 11 graft failures $(11.0 \%)$. Trauma was the preoperative indication in 8 patients $(8.0 \%)$. Glaucoma-associated corneal decompensation and corneal decompensation of other origin were the preoperative diagnosis for 7 patients with graft failure (7.0\%). The remaining patients with graft failure had Fuchs endothelial dystrophy (4 patients, $4.0 \%$ ), corneal scar (3 patients, $3.0 \%$ ), chemical burn ( 3 patients, $3.0 \%$ ), keratoconus ( 2 patients, $2.0 \%$ ), and stromal dystrophies of the cornea (1 patient, $1.0 \%)$. Most indications for penetrating keratoplasty were found to be significantly associated with graft failure in the univariate regression analysis. Multivariate analysis showed a significant association between graft failure and the indications infectious keratitis, imminent or acute perforation of noninfectious corneal ulceration, preoperative graft failure, chemical burn, trauma, glaucoma-associated corneal decompensation, and corneal decompensation of other origin (Tables 2 and 3). The most common indications among the 277 non-graft failure patients were keratoconus ( 98 patients, $35.4 \%$ ), Fuchs endothelial dystrophy (33 patients, $11.9 \%$ ) and bullous keratopathy (29 patients, $10.5 \%$ ).

\section{High-Risk Keratoplasties}

According to the literature, there are various pathologies and diseases that have previously been categorized as risk factors for high-risk keratoplasties including corneal vascularization, repeat keratoplasty, emergency penetrating keratoplasty, limbal keratoplasty, severe ocular surface disease, herpetic keratitis, acanthamoeba keratitis, uncontrolled glaucoma, reduced compliance, and corneal diseases in infants. Among the 377 patients in our study, there were $167(44.3 \%)$ high-risk patients and $210(55.7 \%)$ normal-risk patients. Whereas $77(46.1 \%)$ of the high-risk patients had graft failure, only 23 (11.0\%) of the normal-risk patients had graft failure.

In this study, all the mentioned risk factors for high-risk keratoplasties were statistically significantly associated with graft failure except for corneal diseases in infants. In the multivariate analysis, however, a significant association for graft failure was only found for the number of penetrating keratoplasties, emergency penetrating keratoplasty, penetrating limbal-keratoplasty, acanthamoeba keratitis, and uncontrolled glaucoma (Tables 4 and 5).

TABLE 2. Univariate Analysis of Demographic and Baseline Variables

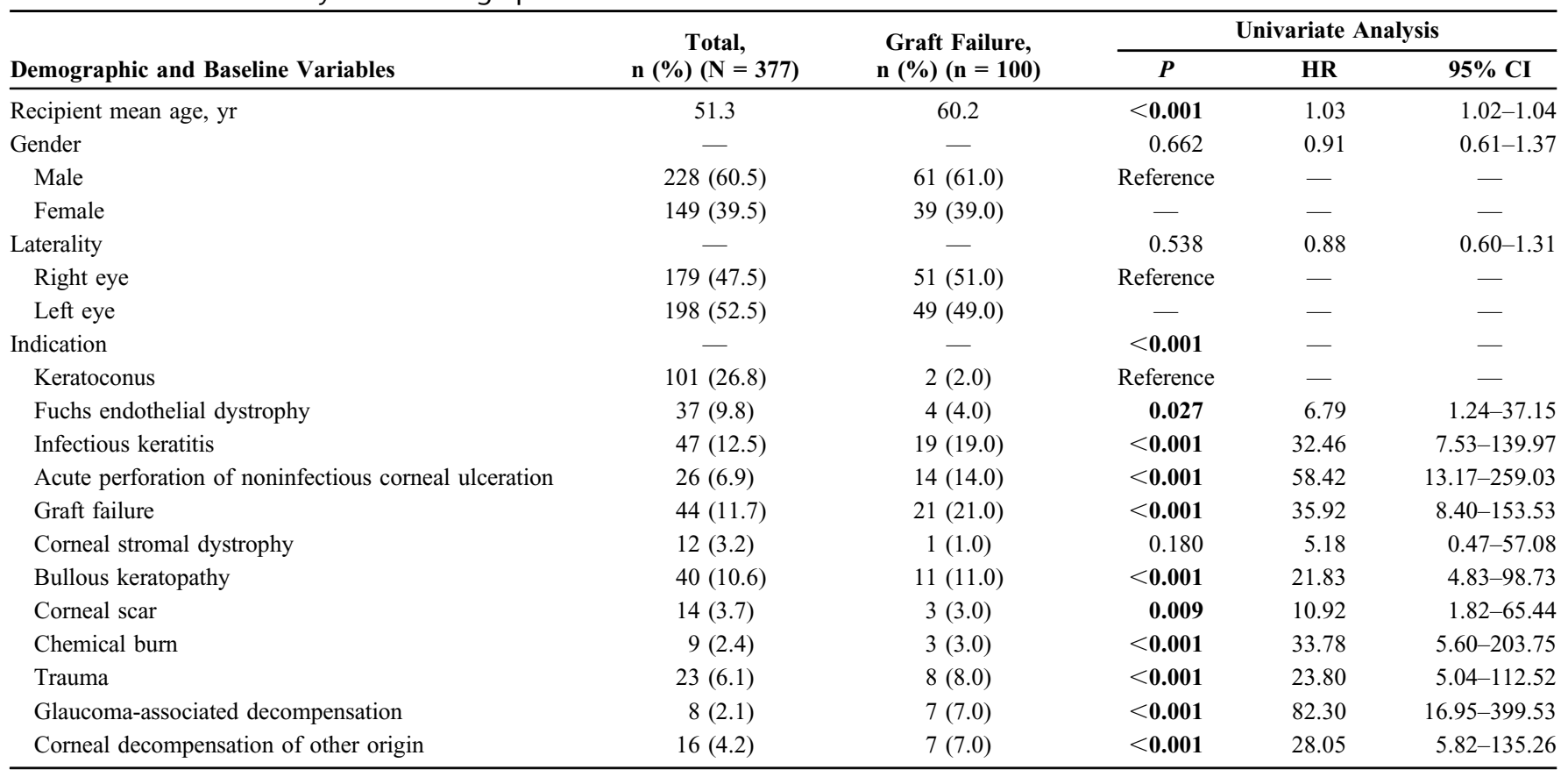

CI, confidence interval. 
TABLE 3. Multivariate Analysis of Demographic and Baseline Variables

\begin{tabular}{|c|c|c|c|c|c|}
\hline \multirow[b]{2}{*}{ Demographic and Baseline Variables } & \multirow{2}{*}{$\begin{array}{c}\text { Total, } \\
\text { n }(\%)(\mathbf{N}=377)\end{array}$} & \multirow{2}{*}{$\begin{array}{l}\text { Graft Failure, } \\
\text { n (\%) }(n=100)\end{array}$} & \multicolumn{3}{|c|}{ Multivariate Analysis } \\
\hline & & & $\boldsymbol{P}$ & HR & $95 \% \mathrm{CI}$ \\
\hline Recipient mean age, yr & 51.3 & 60.2 & 0.024 & 1015.00 & $1.00-1.03$ \\
\hline Keratoconus & $101(26.8)$ & $2(2.0)$ & Reference & - & - \\
\hline Infectious keratitis & $47(12.5)$ & $19(19.0)$ & 0.006 & 8.93 & $1.89-42.24$ \\
\hline Acute perforation of noninfectious corneal ulceration & $26(6.9)$ & $14(14.0)$ & $<\mathbf{0 . 0 0 1}$ & 32.33 & $6.59-158.76$ \\
\hline Corneal scar & $14(3.7)$ & $3(3.0)$ & 0.068 & 5.57 & $0.88-35.23$ \\
\hline Chemical burn & $9(2.4)$ & $3(3.0)$ & 0.026 & 9.53 & $1.30-69.77$ \\
\hline Trauma & $23(6.1)$ & $8(8.0)$ & 0.001 & 15.78 & $3.04-81.98$ \\
\hline Glaucoma-associated decompensation & $8(2.1)$ & $7(7.0)$ & 0.006 & 13.76 & $2.13-88.80$ \\
\hline Corneal decompensation of other origin & $16(4.2)$ & $7(7.0)$ & 0.004 & 11.49 & $2.20-59.85$ \\
\hline
\end{tabular}

CI, confidence interval.

\section{Preoperative Ocular Conditions}

Among the preoperative ocular conditions, corneal edema, status postretinal surgery, pseudophakia, aphakia, and anterior chamber lens were significantly associated with graft failure in the univariate analyses. In the multivariate analysis, preoperative corneal edema and anterior chamber lens were significant risk factors for graft failure (Tables 6 and 7).

\section{Preoperative Systemic Diseases}

Among the preoperative systemic diseases, diabetes mellitus, atopy, rheumatoid arthritis, and other autoimmune diseases were significant factors for graft failure. However, the different forms of atopy, for example, bronchial asthma and atopic dermatitis, did not show significant associations with graft failure rates. In addition, thyroid disease was not significantly associated with graft failure. In the multivariate analysis,

TABLE 4. Univariate Analysis of Variables for High-Risk Keratoplasties

\begin{tabular}{|c|c|c|c|c|c|}
\hline \multirow[b]{2}{*}{ Variables for High-Risk Keratoplasties } & \multirow[b]{2}{*}{ Total, n $(\%)(\mathbf{N}=377)$} & \multirow[b]{2}{*}{ Graft Failure, $n(\%)(n=100)$} & \multicolumn{3}{|c|}{ Univariate Analysis } \\
\hline & & & $\boldsymbol{P}$ & HR & $95 \% \mathrm{CI}$ \\
\hline High risk & $167(44.3)$ & $77(77.0)$ & $<\mathbf{0 . 0 0 1}$ & 6.00 & $3.74-9.62$ \\
\hline Corneal vascularization & $79(21.0)$ & $34(34.0)$ & $<\mathbf{0 . 0 0 1}$ & 2.21 & $1.46-3.34$ \\
\hline Anterior synechia & $30(8.0)$ & $8(8.2)$ & 0.744 & 1.13 & $0.55-2.33$ \\
\hline Repeated keratoplasty & $64(17.0)$ & $29(29.0)$ & $<0.001$ & 2.45 & $1.59-3.79$ \\
\hline Number of keratoplasties & 1.2 & 1.4 & $<\mathbf{0 . 0 0 1}$ & 1.96 & $1.45-2.65$ \\
\hline 3 & $17(4.5)$ & $9(9.0)$ & - & - & - \\
\hline Emergency keratoplasty & $15(4.0)$ & $10(10.0)$ & $<0.001$ & 6.14 & $3.14-12.01$ \\
\hline Limbo-keratoplasty & $8(2.1)$ & $5(5.0)$ & 0.005 & 3.60 & $1.46-8.89$ \\
\hline Severe ocular surface disease & $16(4.2)$ & $8(8.0)$ & 0.014 & 2.49 & $1.21-5.13$ \\
\hline Limbal stem cell insufficiency & $15(4.0)$ & $9(9.0)$ & 0.001 & 3.28 & $1.65-6.54$ \\
\hline Herpes keratitis & $47(12.5)$ & $20(20.0)$ & 0.002 & 2.20 & $1.34-3.61$ \\
\hline After glaucoma surgery & - & - & $<0.001$ & - & - \\
\hline None & $354(93.9)$ & $82(82.0)$ & Reference & - & - \\
\hline Trabeculectomy & $19(5.0)$ & $15(15.0)$ & $<\mathbf{0 . 0 0 1}$ & 4.45 & $2.56-7.74$ \\
\hline Cyclophotocoagulation & $4(1.1)$ & $3(3.0)$ & 0.042 & 3.33 & $1.05-10.57$ \\
\hline Reduced compliance & $33(8.8)$ & $14(14.0)$ & 0.022 & 1.94 & $1.10-3.41$ \\
\hline Infants & $28(7.4)$ & $5(5.0)$ & 0.425 & 0.69 & $0.28-1.71$ \\
\hline
\end{tabular}

CI, confidence interval. 
TABLE 5. Multivariate Analysis of Variables for High-Risk Keratoplasties

\begin{tabular}{|c|c|c|c|c|c|}
\hline \multirow[b]{2}{*}{ Variables for High-Risk Keratoplasties } & \multirow{2}{*}{$\begin{array}{c}\text { Total, } \\
\text { n (\%) }(\mathbf{N}=377)\end{array}$} & \multirow{2}{*}{$\begin{array}{l}\text { Graft Failure, } \\
\text { n (\%) }(n=100)\end{array}$} & \multicolumn{3}{|c|}{ Multivariate Analysis } \\
\hline & & & $P$ & HR & $95 \%$ CI \\
\hline High risk & $167(44.3)$ & $77(77.0)$ & - & - & - \\
\hline Corneal vascularization & $79(21.0)$ & $34(34.0)$ & 0.179 & - & - \\
\hline Repeated keratoplasty & $64(17.0)$ & $29(29.0)$ & 0.396 & - & - \\
\hline Number of keratoplasties & 1.2 & 1.4 & 0.036 & 1.92 & $1.04-3.53$ \\
\hline 1 & $313(83.0)$ & $71(71.0)$ & - & - & - \\
\hline Emergency keratoplasty & $15(4.0)$ & $10(10.0)$ & 0.026 & 2.80 & $1.13-6.90$ \\
\hline Limbo-keratoplasty & $8(2.1)$ & $5(5.0)$ & 0.006 & 4.65 & $1.56-13.88$ \\
\hline Limbal stem cell insufficiency & $15(4.0)$ & $9(9.0)$ & 0.106 & - & - \\
\hline Herpes keratitis & $47(12.5)$ & $20(20.0)$ & 0.54 & - & - \\
\hline Acanthamoeba keratitis & $4(1.1)$ & $3(3.0)$ & $<\mathbf{0 . 0 0 1}$ & 30.22 & $7.59-120.28$ \\
\hline Uncontrolled glaucoma & $21(5.6)$ & $18(18.0)$ & 0.01 & 2.76 & $1.28-5.97$ \\
\hline
\end{tabular}

diabetes mellitus, atopy, and autoimmune diseases showed significant associations with graft failure (Tables 8 and 9).

\section{DISCUSSION}

Multiple factors may influence the outcome of corneal transplantation. Risk factors concerning the donor corneas may depend on the way donor corneas were processed, the demographic data of the donors including age and death to enucleation time, or the storage time of organ-cultured donor corneas. Among the donor-related risk factors, only the donor age $(\mathrm{HR}=1.02 ; P<0.001)$ and the endothelial cell density $(\mathrm{HR}=0.99 ; P=0.004)$ were significantly associated with graft failure in our study. Our statistical analyses by Pearson linear regression demonstrated that the donor age also had a highly significant negative correlation with the endothelial cell density $(P<0.001, \mathrm{r}=-0.382)$. This means that increasing donor age is significantly associated with loss of endothelial cell density. Previous studies have shown that the corneal endothelial cell density, rather than the donor age, is the determinant factor for long-term graft survival. ${ }^{11}$
In practical terms, it may be concluded that the evaluation of the quality of the donor cornea including the endothelial cell density has a greater importance for the graft outcome than assessing the donor age alone. ${ }^{12}$ Our results were consistent with the results of the Cox multivariate regression analysis by Williams et al. ${ }^{13}$ The Cornea Donor Study Investigator Group $^{12}$ also demonstrated no significant influence of donor age on the 5-year survival rate of corneal transplants. Therefore, it was concluded that corneas with adequate endothelial cell densities from donors up to 75 years of age were suitable for transplantation. Other donor cornea characteristics such as death to enucleation time, storage time, or the surgeons' assessment of the clarity or rigidity of donor cornea were not significantly associated with graft failure. These results were in accordance with previous studies, which also did not find any association between donor cornea characteristics and graft failure. ${ }^{4,14}$ This lacking association may be attributed to standardized eye bank procedures including donor screening, tissue processing, and corneal graft evaluation before keratoplasty, which have been implemented throughout the world. It also confirms the validity of organ

TABLE 6. Univariate Analysis of Preoperative Ocular Variables

\begin{tabular}{|c|c|c|c|c|c|}
\hline \multirow[b]{2}{*}{ Preoperative Ocular Variables } & \multirow[b]{2}{*}{ Total, n $(\%)(\mathbf{N}=377)$} & \multirow[b]{2}{*}{ Graft Failure, $n(\%)(n=100)$} & \multicolumn{3}{|c|}{ Univariate Analysis } \\
\hline & & & $P$ & HR & $95 \% \mathrm{CI}$ \\
\hline Corneal edema & $80(21.2)$ & $39(39.0)$ & $<0.001$ & 3.12 & $2.08-4.68$ \\
\hline After retinal surgery & $33(8.8)$ & $19(19.0)$ & $<\mathbf{0 . 0 0 1}$ & 2.61 & $1.58-4.30$ \\
\hline Lens status & - & - & $<\mathbf{0 . 0 0 1}$ & - & - \\
\hline Phakic & $229(60.7)$ & $35(35.0)$ & Reference & - & - \\
\hline Pseudophakic & $96(25.5)$ & $40(40.0)$ & $<\mathbf{0 . 0 0 1}$ & 3.62 & $2.29-5.71$ \\
\hline Aphakic & $37(9.8)$ & $16(16.0)$ & $<\mathbf{0 . 0 0 1}$ & 3.20 & $1.77-5.78$ \\
\hline Anterior chamber lens & $15(4.0)$ & $9(9.0)$ & $<\mathbf{0 . 0 0 1}$ & 5.94 & $2.84-12.46$ \\
\hline
\end{tabular}


TABLE 7. Multivariate Analysis of Preoperative Ocular Variables

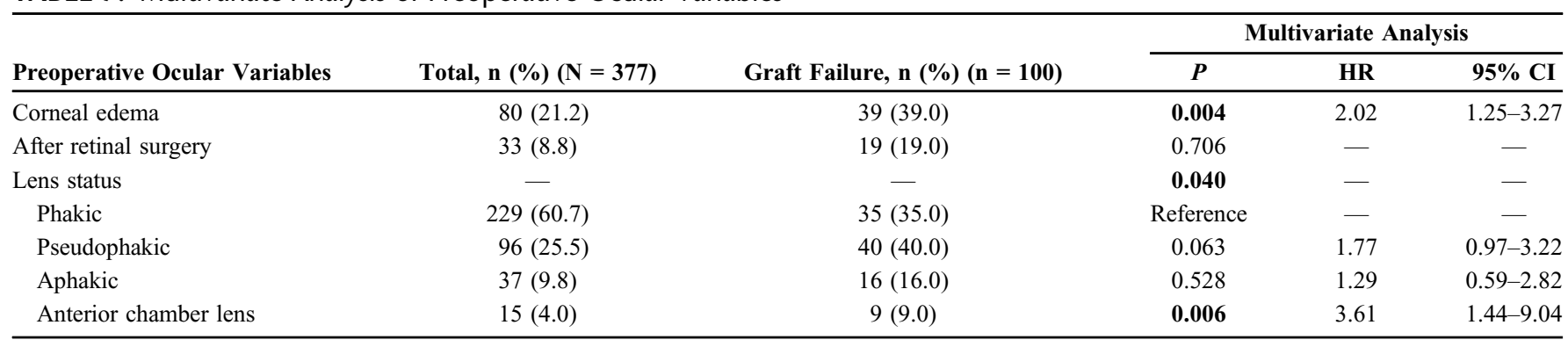

CI, confidence interval.

culture, a method that has been used as an established preservation technique for donor corneas since $1976 .{ }^{15}$

Besides these few donor-related risk factors, the clinical outcome of corneal grafts is mostly determined by the preoperative factors of the recipient. We did not find any significant association between graft failure and the patients' demographic characteristics except for the patient age. This observation may be explained by the fact that the endothelial cell density decreases with increasing age of the patient. Therefore, a higher number of graft failures in elderly patients may be in part a resultant of their decreased endothelial cell density in the remaining corneal bed with age. ${ }^{16}$ In contrast to our study, Sugar et $\mathrm{al}^{5}$ did not find any significant association between the patient age and graft failure neither in the univariate analysis nor in the multivariate analysis. They only included patients with moderate-risk conditions in their analyses, whereas our study included patients with rather highrisk corneal conditions or conditions of multiple confounding diseases.

Among the preoperative indications for penetrating keratoplasties, infectious keratitis, imminent or acute perforation of noninfectious corneal ulceration, preoperative graft failure, chemical burn, trauma, and glaucoma-associated corneal decompensation were significant risk factors for graft failure in the multivariate analyses. These indications are typical for high-risk keratoplasties. ${ }^{17-20}$ The only graft indication for high-risk keratoplasties, which was not significantly associated with graft failure in our study, was pediatric keratoplasty. The reason for this exception may be the low number of grafts in infants among our study population, an intensive and effective postoperative treatment in our university setting, or graft failure after the time points analyzed for this study.

Another ocular condition, which may determine the risk of graft failure, is the preoperative lens status of the patient. In comparison with phakic eyes, the risk of graft failure is significantly increased in eyes with anterior chamber lens implantation $(\mathrm{HR}=3.61, P=0.006)$, whereas pseudophakic and aphakic eyes had no increased risk for graft failure. In accordance with our results, Sugar et $\mathrm{al}^{5}$ found that the presence of an anterior chamber lens led to a 2-fold higher risk of graft failure than the presence of a posterior chamber lens after corneal transplantation. Besides that, Yamagami et al, ${ }^{21}$ Inoue et al, ${ }^{22}$ and Fasolo et $\mathrm{al}^{3}$ detected a higher risk for graft failure also among pseudophakic and aphakic eyes.

TABLE 8. Univariate Analysis of Preoperative Systemic Variables

\begin{tabular}{|c|c|c|c|c|c|}
\hline \multirow[b]{2}{*}{ Preoperative Systemic Variables } & \multirow[b]{2}{*}{ Total, n (\%) $(\mathbf{N}=377)$} & \multirow[b]{2}{*}{ Graft Failure, n (\%) $(n=100)$} & \multicolumn{3}{|c|}{ Univariate Analysis } \\
\hline & & & $P$ & HR & $95 \%$ CI \\
\hline Syndrome & - & - & 0.338 & - & - \\
\hline None & $354(93.9)$ & $91(91.0)$ & Reference & - & - \\
\hline Others & $15(4.0)$ & $6(6.0)$ & 0.153 & 1.83 & $0.80-4.18$ \\
\hline Trisomia 21 & $8(2.1)$ & $3(3.0)$ & 0.670 & 1.29 & $0.41-4.06$ \\
\hline Diabetes mellitus & $39(10.3)$ & $21(21.0)$ & $<\mathbf{0 . 0 0 1}$ & 2.61 & $1.61-4.23$ \\
\hline Asthma & $16(4.3)$ & $4(4.0)$ & 0.963 & 0.98 & $0.36-2.67$ \\
\hline Atopic dermatitis & $9(2.4)$ & $4(4.0)$ & 0.158 & 2.06 & $0.75-5.64$ \\
\hline Other autoimmune disease & $4(1.1)$ & $4(4.0)$ & $<\mathbf{0 . 0 0 1}$ & 18.52 & $6.44-53.26$ \\
\hline Rheumatoid arthritis & $17(4.5)$ & $8(8.0)$ & 0.034 & 2.20 & $1.06-4.55$ \\
\hline Thyroid disease & $53(14.1)$ & $17(17.0)$ & 0.401 & 1.25 & $0.74-2.11$ \\
\hline
\end{tabular}

CI, confidence interval. 
TABLE 9. Multivariate Analysis of Preoperative Systemic Variables

\begin{tabular}{|c|c|c|c|c|c|}
\hline \multirow[b]{2}{*}{ Preoperative Systemic Variables } & \multirow[b]{2}{*}{ Total, n $(\%)(\mathbf{N}=377)$} & \multirow[b]{2}{*}{ Graft Failure, $n(\%)(n=100)$} & \multicolumn{3}{|c|}{ Multivariate Analysis } \\
\hline & & & $P$ & HR & $95 \% \mathrm{CI}$ \\
\hline Diabetes mellitus & $39(10.3)$ & $21(21.0)$ & $<0.001$ & 3.06 & $1.69-5.54$ \\
\hline Atopy & - & - & 0.018 & - & - \\
\hline None & $331(87.8)$ & $80(80.0)$ & Reference & - & - \\
\hline Asthma & $16(4.3)$ & $4(4.0)$ & 0.184 & 2.09 & $0.71-6.20$ \\
\hline Atopic dermatitis & $9(2.4)$ & $4(4.0)$ & 0.432 & 1.60 & $0.49-5.19$ \\
\hline
\end{tabular}

CI, confidence interval.

Interestingly, also preoperative corneal edema of any origin was shown to be a risk factor in both the univariate and multivariate analyses $(\mathrm{HR}=2.02 ; P=0.004)$. Preoperative corneal edema is a serious obstacle in assessing the preoperative status of the eye. Vail et $\mathrm{al}^{23}$ also found that preoperative corneal edema is associated with a significantly higher risk of graft failure. These results may help us to assess the graft outcome by an aspect of the clinical corneal presentation independent of the indication.

Among the preoperative accompanying systemic diseases, diabetes mellitus, atopy, and autoimmune diseases were significantly associated with graft failure. These observations were not surprising given that atopic patients are at a greater risk for ocular inflammation due the release of inflammatory mediators. ${ }^{24}$ Price et $\mathrm{al}^{25}$ also identified diabetes mellitus as an important risk factor for graft failure, which may be related to diabetic nerve fiber degeneration in the cornea. ${ }^{26}$ However, Sugar et $\mathrm{al}^{5}$ did not find any significant association between diabetes mellitus and graft failure, but they also excluded eyes with high or very low risk for graft failure.

There are several limitations of this study, which need to be addressed: On the one hand, 1 exclusion criterion is a short follow-up period of less than 1 year. Therefore, a selection bias could not be ruled out. Furthermore, the study design may be biased by excluding patients with nonpenetrating forms of keratoplasties such as Descemet stripping automated endothelial keratoplasty. These patients were excluded because a follow-up period of at least 1 year could not be obtained at the time when this study was conducted. On the other hand, the study included a large proportion of patients with keratoconus $(27 \%)$, who are known to have a low incidence of graft failure. This fact must be taken into account when comparing with studies that excluded patients with keratoconus.

In conclusion, this study demonstrated that both donorrelated factors and recipient-related preoperative factors might influence the risk of graft failure. Our analyses included the evaluation of corneal graft outcomes with organ-cultured donor corneas during a 10-year period at our University Eye Hospital, Munich, Germany. The knowledge about potential risk factors for graft failure may help us to better assess the prognosis of corneal transplantation especially in a diverse patient population such as in our university setting.

\section{ACKNOWLEDGMENTS}

The data in this study are part of the medical thesis of Michaela Kaiser at the Medical School of the LudwigMaximilians-University, Munich, Germany.

\section{REFERENCES}

1. Hori J. Mechanisms of immune privilege in the anterior segment of the eye: what we learn from corneal transplantation. J Ocul Biol Dis Infor. 2008;1:94-100.

2. Niederkorn JY, Mellon J. Anterior chamber-associated immune deviation promotes corneal allograft survival. Invest Ophthalmol Vis Sci. 1996;37: 2700-2707.

3. Fasolo A, Capuzzo C, Fornea M, et al; CORTES Study Group. Risk factors for graft failure after penetrating keratoplasty: 5-year follow-up from the corneal transplant epidemiological study. Cornea. 2011;30: 1328-1335.

4. Sugar J, Montoya M, Dontchev M, et al; Cornea Donor Study Investigator Group. Donor risk factors for graft failure in the cornea donor study. Cornea. 2009;28:981-985.

5. Sugar A, Tanner JP, Dontchev M, et al; Cornea Donor Study Investigator Group. Recipient risk factors for graft failure in the cornea donor study. Ophthalmology. 2009;116:1023-1028.

6. Williams KA, Lowe M, Bartlett C, et al. Risk factors for human corneal graft failure within the Australian corneal graft registry. Transplantation. 2008;86:1720-1724.

7. Zirm E. Eine erfolgreiche totale Keratoplastik. Archiv Fur Ophthalmol. 1906;64:580-593.

8. Sundmacher R, Reinhard T. Bedarfsdeckung mit qualitätsgesicherten Hornhautimplantaten Rolle der Hornhautbanken und der Kostenträger in Deutschland. Der Ophthalmologe. 2001;98:277-284.

9. Eye Bank Association of America. 2008 Eye Banking Statistical Report. Washington, DC: Eye Bank Association of America; 2009:1-17.

10. Claerhout I, Maas H, Pels E. European Eye Bank Association. 18th ed. Barcelona, Spain: EEBA Directory; 2010.

11. Armitage WJ, Dick AD, Bourne WM. Predicting endothelial cell loss and long-term corneal graft survival. Invest Ophthalmol Vis Sci. 2003;44: 3326-3331.

12. Cornea Donor Study Investigator Group, Gal RL, Dontchev M, Beck RW, et al. The effect of donor age on corneal transplantation outcome results of the cornea donor study. Ophthalmology. 2008;115:620-626.e6.

13. Williams KA, Esterman AJ, Bartlett C, et al. How effective is penetrating corneal transplantation? Factors influencing long-term outcome in multivariate analysis. Transplantation. 2006;81:896-901.

14. Patel SV, Diehl NN, Hodge DO, et al. Donor risk factors for graft failure in a 20-year study of penetrating keratoplasty. Arch Ophthalmol. 2010; 128:418-425.

15. Pels E, Beele H, Claerhout I. Eye bank issues: II. Preservation techniques: warm versus cold storage. Int Ophthalmol. 2008;28:155-163.

16. Sit M, Weisbrod DJ, Naor J, et al. Corneal graft outcome study. Cornea. 2001;20:129-133.

17. Vajpayee RB, Sharma N, Sinha R, et al. Infectious keratitis following keratoplasty. Surv Ophthalmol. 2007;52:1-12. 
18. Chong EM, Dana MR. Graft failure IV. Immunologic mechanisms of corneal transplant rejection. Int Ophthalmol. 2008;28:209-222.

19. Portnoy SL, Insler MS, Kaufman HE. Surgical management of corneal ulceration and perforation. Surv Ophthalmol. 1989;34:47-58.

20. Reinhard T, Kallmann C, Cepin A, et al. The influence of glaucoma history on graft survival after penetrating keratoplasty. Graefes Arch Clin Exp Ophthalmol. 1997;235:553-557.

21. Yamagami S, Suzuki Y, Tsuru T. Risk factors for graft failure in penetrating keratoplasty. Acta Ophthalmol Scand. 1996;74:584-588.

22. Inoue $\mathrm{K}$, Amano S, Oshika T, et al. Risk factors for corneal graft failure and rejection in penetrating keratoplasty. Acta Ophthalmol Scand. 2001; $79: 251-255$.
23. Vail A, Gore SM, Bradley BA, et al. Conclusions of the corneal transplant follow up study. Collaborating Surgeons. Br J Ophthalmol. 1997; 81:631-636.

24. Reinhard T, Möller M, Sundmacher R. Penetrating keratoplasty in patients with atopic dermatitis with and without systemic cyclosporin A. Cornea. 1999; 18:645-651.

25. Price MO, Thompson RW Jr, Price FW Jr. Risk factors for various causes of failure in initial corneal grafts. Arch Ophthalmol. 2003;121: $1087-1092$.

26. Messmer EM, Schmid-Tannwald C, Zapp D, et al. In vivo confocal microscopy of corneal small fiber damage in diabetes mellitus. Graefes Arch Clin Exp Ophthalmol. 2010;248:1307-1312. 